The cases described in the present report implicate fenbufen in causing an adverse reaction that presents as a florid rash followed by a severe, short lived reversible illness whose characteristic feature is a pulmonary eosinophilia.

I thank the Committee on Safety of Medicines for permission to report these cases and the doctors who originally submitted the reports for providing further clinical details.
1 O'Brien WM, Bagby GF. Rare adverse reactions to non-steroidal antiinflammatory drugs. F Rheumatol 1985;12:13-20.

Flint KC, Johnson NM. Pulmonary eosinophilia associated with naproxen therapy. F $R$ Soc Med 1987;80:120-1.

Stromberg C, Palva E, Alhava E, Aranko K, Idanpaan-Haikkila J. Pulmonary infiltrations induced by tolfenamic acid. Lancet 1987;ii:685.

4 Gheysens B, Van Miegham W. Pulmonary infiltrates with eosinophilia due to glafenine. Eur F Respir Dis 1984;65:456-9.

Chuck AJ, Wilcox M, Bossingham DH. Fenbufen-associated pneumonitis. Br f R Reumatol 1987;26:475-6.

(Accepted 12 September 1989)
Prince of Wales Hospital, Chinese University of Hong Kong, Shatin, New Territories, Hong Kong S Michael Griffin, FRCS, visiting lecturer in surgery S C Sydney Chung, MD, senior lecturer in surgery Joseph W C Leung, MD, senior lecturer in medicine Arthur K C Li, MD, professor of surgery

Correspondence to: Professor Li.

\section{Effect of intranasal oxygen on hypoxia and tachycardia during endoscopic cholangiopancreatography}

\author{
S Michael Griffin, S C Sydney Chung, \\ Joseph W C Leung, Arthur K C Li
}

Most patients tolerate endoscopic procedures well, although complications occur occasionally. Cardiopulmonary complications are the commonest and occur once in every 1600 investigations. ' We found that $44 \%$ of patients who had endoscopic retrograde cholangiopancreatography became hypoxic. ${ }^{2}$ Factors that contribute to hypoxia include advancing age, preexisting lung disease, increasing intravenous sedation, and the diameter of the endoscope. ${ }^{34}$ We carried out a randomised controlled study to assess whether administration of oxygen intranasally prevents such hypoxia.

\section{Patients, methods, and results}

We studied 80 consecutive patients undergoing elective endoscopic cholangiopancreatography, who were randomised to receive intranasal oxygen or serve as controls. Pulse oximetry was performed during the procedure with an Oxyshuttle oximeter and Transend strip recorder (Sensorimedics) with the sensor attached to an index finger. Blood pressure was measured at one minute intervals with a Dinamap monitor. Patients lay supine for one minute to establish baseline values and then turned to the prone position. The throat was sprayed with local anaesthetic, and intravenous diazepam and pethidine were administered at doses left to the endoscopist's discretion. Endoscopy was started one minute later. Oxygen $(4.5 \mathrm{l} / \mathrm{min})$ was administered intranasally to the patients randomised to receive it as soon as they were prone. Age, weight, doses of diazepam and pethidine, and length of procedure were subjected to multiple regression analysis to determine predictors of hypoxia, tachycardia, and hypotension.

Forty one patients (19 men, 22 women) served as controls and 39 (21 men, 18 women) were given oxygen. The two groups were similar in age (mean (SEM) $60 \cdot 5(2 \cdot 2) v 61 \cdot 0(2 \cdot 6))$, weight $(55 \cdot 8(1 \cdot 3) v 52 \cdot 6$ $(1 \cdot 6) \mathrm{kg}$ ), duration of procedure $(28 \cdot 2(2 \cdot 8) v 27 \cdot 8(2 \cdot 4)$ $\mathrm{min})$, and doses of pethidine $(25.8(1.6) v 23.4(1.5)$ $\mathrm{mg})$ and diazepam $(4 \cdot 6(0.3) v 4 \cdot 1(0 \cdot 3) \mathrm{mg})$. The incidence of cardiac disease (five $v$ seven patients) and of previous respiratory infection ( $19 v 20$ patients) were comparable between the two groups.

The figure shows mean oxygen saturation in the two groups. At the start of endoscopy oxygen saturation in both groups fell sharply and then rose. Mean oxygen saturation was higher throughout the procedure in the patients who received oxygen. Oxygen saturation dropped below $90 \%$ for more than 60 seconds at some point during the procedure in 21 controls and four patients given oxygen $(\mathbf{p}<0.001$, Fisher's exact test). In three patients (two controls and one given oxygen) it fell below $80 \%$, but only one of these patients was cyanosed. These patients received naloxone.

No significant difference in pulse rate or blood pressure was detected between the controls and the group given oxygen, but those patients with oxygen saturations below $90 \%$ had a significantly higher pulse rate than those who were not hypoxic $(p<0.05)$. Increasing age correlated with a lower oxygen saturation in both groups (group given oxygen $\mathrm{p}<0.01, \mathrm{r}=0.512$; controls $\mathrm{p}<0.01, \mathrm{r}=0.464)$. Increasing dose of pethidine correlated with desaturation only in the control group $(p<0.02, r=0.574)$. Body weight, length of procedure, and dose of diazepam given did not show a positive correlation.

\section{Comment}

Compared with gastroscopy endoscopic retrograde cholangiopancreatography poses several problems. Patients undergoing the procedure are normally older; a duodenoscope is larger than a gastroscope; the procedure is more complicated, is more unpleasant, and may take longer; heavier sedation may be necessary; and the patient is obscured by the $x$ ray machine, making monitoring more difficult.

We found that hypoxia was common during endoscopic retrograde cholangiopancreatography and occurred within the first 15 minutes; tachycardia occurred during these hypoxic episodes, suggesting that the oxygen desaturation is clinically important. Oxygen desaturation associated with tachycardia can result in myocardial ischaemia in patients with borderline coronary perfusion. ${ }^{5}$ The hypoxia during endoscopic retrograde cholangiopancreatography was prevented in all but four of 39 patients given intranasal oxygen at a dose of $4.5 \mathrm{l} / \mathrm{min}$. Monitoring of pulse

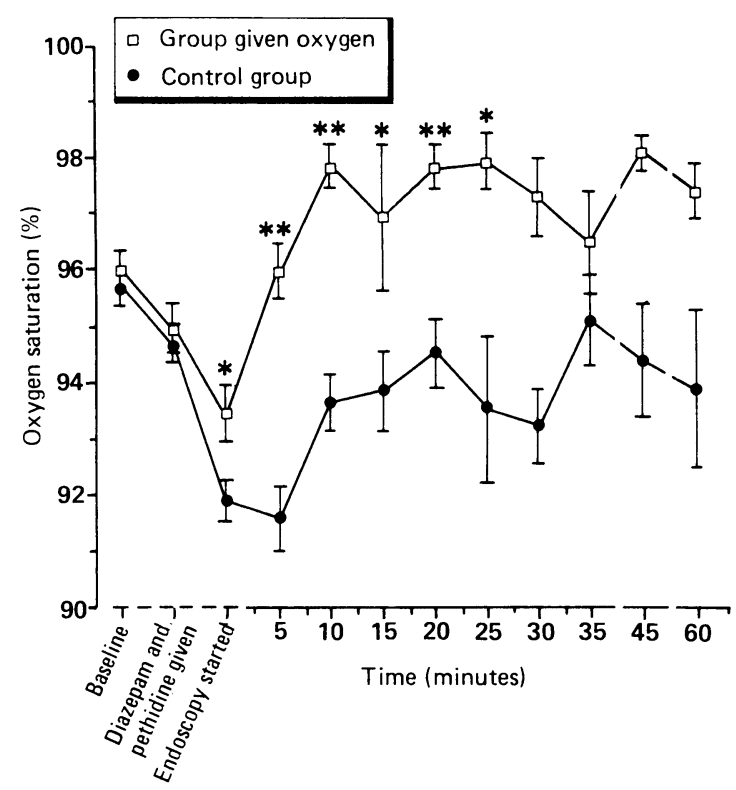

Mean (SEM) oxygen saturation in 39 patients given intranasal oxygen and 41 controls during endoscopic retrograde cholangiopancreatography. ${ }^{\star} p<0.01 ;{ }^{\star \star} p<0.001$ 
oximetry and intranasal administration of oxygen are thus advisable during the procedure.

1 Schiller KFR, Cotton PB, Salmon PR. The hazards of digestive fibre endoscopy. A survey of British experience. Gut 1972;13:1027.

2 Woods SDS, Chung SCS, Leung JWC, Chan ACW, Li AKC. Hypoxia and tachycardia during endoscopic retrograde cholangiopancreatography: detection by pulse oximetry. Gastrointest Endosc (in press).
3 Lieberman DA, Wuerker CK, Katon RM. Cardiopulmonary risk of esophagogastroduodenoscopy. Gastroenterology 1985;88:458-72.

Rozen P, Oppenheim D, Ratan J, Laniado S, Gilat T. Arterial oxygen tension changes in elderly patients undergoing upper gastrointestinal endoscopy 1. Possible causes. Scand f Gastroenterol 1979;14:577-81.

5 Hoffman JIE, Buckberg JD. Regional myocardial ischaemia - causes, prediction and prevention. Vasc Surg 1974;8:115-30.

(Accepted 15 September 1989)

\section{The oesophagus in lichen planus: an endoscopic study}

\author{
Christopher M Dickens, David Heseltine, \\ Shernaz Walton, John R Bennett
}

\section{Hull Royal Infirmary, Hull, North Humberside} HU3 2JZ

Christopher M Dickens, MB, senior house officer, department of medicine David Heseltine, MRCP, senior registrar, department of medicine and gastroenterology Shernaz Walton, MD, senior registrar, department of dermatology

John R Bennett, MD, consultant gastroenterologist

Correspondence and requests for reprints to: $\mathrm{Dr}$ Bennett.

BrMed f 1990;300:84 scopy would benefit all patients with the disease.

\section{Patients, methods, and results}

Lichen planus is a common condition of unknown aetiology. Oral disease is common, occurring in 30 $70 \%$ of cases, but premalignant oesophageal disease is considered to be extremely rare ${ }^{1-4}$ (only about 10 cases have been reported). Oesophageal disease may result in dysphagia $^{1-4}$ and the formation of benign strictures. ${ }^{2+}$ In view of the increased risk of malignant change with oral lichen planus ${ }^{12}$ chronic erosive changes of lichen planus in the oesophagus may also be premalignant, although no such cases have been reported. We carried out a study to establish the prevalence of oesophageal lichen planus and to determine whether routine endo-

We selected for study all patients presenting to the dermatology department at this hospital with active lichen planus between October 1987 and May 1989. We excluded patients who were taking drugs that might produce oesophageal changes or reduce any such changes due to lichen planus and those who were unfit for endoscopy owing to cardiorespiratory disease. Altogether five women and 14 men aged 20 to 66 (mean age 44) were given an endoscopic examination by a single observer. Each patient was questioned about the duration of the disease and the presence or absence of any symptoms of dysphagia, dyspepsia, or regurgitation of acid. An examination was performed to establish the type of cutaneous disease and whether there was any oral disease.

Four patients did not have any visible skin disease, 13 had papular lesions, one had hypertrophic lichen planus, and one had bullous lichen planus. Nine patients did not have any visible oral disease, three had Wickham's striae, four had white plaques, one had disease of the lips, one had minor erosive changes, and one had severe erosive oropharyngeal disease associated with dysphagia.

Five patients had oesophageal lichen planus, of whom four had subtle papular lesions (visible only in the lower third in three cases and throughout the whole oesophagus in one). These changes were different from those that occur in reflux oesophagitis in that superficial layers tended to strip off at biopsy. The patient with dysphagia had severe erosive changes in the whole oesophageal mucosa (figure). A study of the $\mathrm{pH}$ of the oesophagus showed acid reflux well within the normal range. Four of the five patients with oesophageal lichen planus also had oral disease. Histological examination of biopsy specimens of the oesophageal mucosa from the five patients showed submucosal lymphocytic infiltrates consistent with, but not diagnostic of, lichen planus $^{1}$ and quite different from changes induced by acid reflux. The patient with severe oesophageal disease showed a heavy infiltrate of polymorphs, lymphocytes, and plasma cells in the fibromuscular tissue underlying the necrotic areas.

\section{Comment}

We believe this to be the first study attempting to determine the prevalence of oesophageal lichen planus. Though the numbers are small, these results suggest that the prevalence has been greatly underestimated previously: we found that a quarter of people with lichen planus have oesophageal disease. In oral lichen planus $0 \cdot 8-10 \%$ of cases undergo malignant change. If these figures also apply to oesophageal disease a considerable group of people would seem to be at risk of developing carcinoma of the oesophagus, which might be prevented by early treatment.

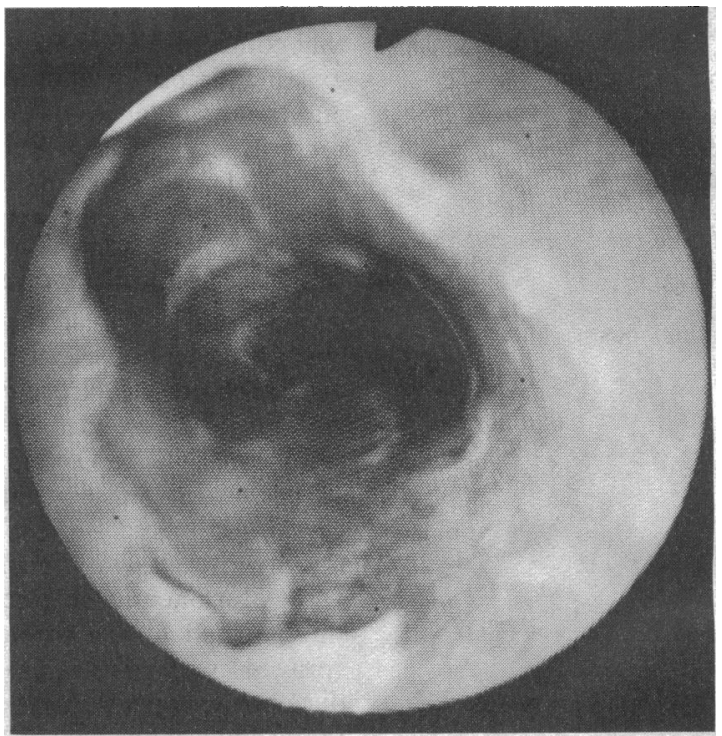

Severe erosive lichen planus of oesophagus seen on endoscopy

We conclude that patients presenting with lichen planus should be questioned about gastrointestinal symptoms and if oesophageal disease is suspected oesophagoscopy should be performed. When severe oesophageal disease is found steroid treatment should probably be started to reduce the symptoms and any strictures $^{124}$ and possibly to decrease any risk of malignant transformation. The benefits of steroid treatment should be confirmed by controlled investigation of a large number of patients.

We thank Dr E H Wyatt and Dr K Keczkes, consultants in dermatology at this hospital, for giving us permission to study their patients and Dr D Piercy, who performed the histological studies.

1 Sheehan-Dare RA, Cotterill JA, Simmons AV. Oesophageal lichen planus. Brf Dermatol 1986;115:729-30.

Jobard-Drobacheff C, Blae D, Quencez E, et al. Lichen planus of the oesophagus. Clin Exp Dermatol 1988;13:38-41.

3 Ler

4 Al-Shihabi BMS, Jackson JM. Dysphagia due to pharyngeal and oesophageal lichen planus. F Laryngol Otol 1982;96:567-71.

5 Altman J, Perry H. The variations and course of lichen planus. Arch Dermato $1961 ; 84: 47-59$

(Accepted 2 October 1989) 